\title{
Concepção de saúde segundo relato de idosos residentes em ambiente urbano*
}

Fátima Ferretti ${ }^{1}$

Rosane Paula Nierotka ${ }^{2}$

Márcia Regina da Silva ${ }^{3}$

FERRETTI, F; NIEROTKA, R.P.; SILVA, M.R. Health conception according to reports of elderly people living in an urban environment. Interface - Comunic., Saude, Educ., v.15, n.37, p.565-72, abr./jun. 2011.

Health is a phenomenon that becomes different according to biological, cultural, environmental, social and historical aspects, and to the way that each human being spends their life. This study aimed to investigate the health conception of elderly people living in an urban environment. It is a descriptive research with a sample of 17 elderly people. Data were collected by means of a semi-structured interview. The data analysis showed that the health conception was centered on the maintenance of independence, on the family's support and on feeling responsible for the way they live their life. Seeing him/ herself as an actor of the process of living and ageing shows that elderly people assume their co-responsibility for their current health condition; this is evidence of change in social and political behavior, from a reactive to a pro-active condition in the process of life.

Keywords: Health. Elderly. Urban environment.
A saúde é um fenômeno que difere de acordo com os aspectos biológicos, culturais, ambientais, sociais e históricos e o modo como cada ser humano viveu sua vida. Este estudo teve como objetivo conhecer a concepção de saúde de idosos residentes em ambiente urbano. Trata-se de pesquisa descritiva com uma amostra de 17 idosos. Na coleta optou-se por uma entrevista semiestruturada. A análise dos dados mostrou que a concepção de saúde está centrada na manutenção da independência, no apoio da família e no sentir-se responsável pelo modo de viver a vida. Perceber-se como ator do processo de viver e envelhecer demonstra que o idoso assume sua corresponsabilização pela saúde vivida hoje, evidenciando uma mudança de comportamento social e político, da passividade para a participação ativa no processo de vida.

Palavras-chave: Saúde. Idoso. Ambiente urbano.

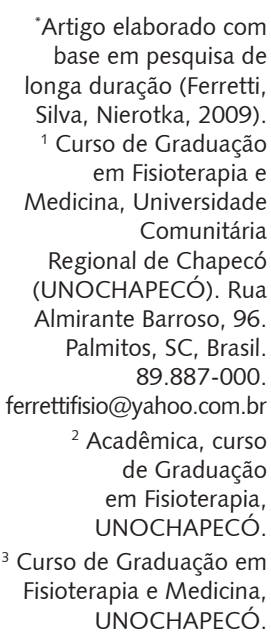
89.887-000 UNOCHAPECÓ. 


\section{Introdução}

Atualmente, "o Brasil é um país que envelhece a passos largos". As mudanças no perfil demográfico populacional são visíveis e irreversíveis. No ano 2000, a população brasileira de idosos cresceu oito vezes mais que a jovem, estando previsto que, em 2025, o Brasil será o sexto país em número de idosos no mundo (Inouye, Pedrazzani, Pavarini, 2008).

A velhice, para alguns, é uma época em que as tarefas básicas em relação ao desempenho profissional e à família, de certo modo, foram cumpridas e o indivíduo pode se sentir livre para realizar seus desejos e sonhos (Ferreira et al., 2009).

Os conceitos saúde e satisfação na velhice têm sido associados a questões de dependência-autonomia, mas deve-se destacar que cada idoso sofre os "efeitos da idade" de diferentes maneiras, pois algumas pessoas apresentam declínio no estado de saúde e nas competências cognitivas precocemente, enquanto outras vivem sem apresentar estas alterações (Joia, Ruiz, Donalisio, 2007).

Lima-Costa et al. (2007) destacam que saúde para idosos é um conceito multidimensional, pois depende da situação socioeconômica, da rede social de apoio, da condição de saúde (destacando-se a saúde mental) e do acesso e uso de serviços de saúde.

O conceito adotado pela Organização Mundial da Saúde (OMS), como "bem estar físico, mental e social do indivíduo", mostra-se inadequado para descrever o universo de saúde dos idosos, já que a ausência de doenças é privilégio de poucos, e o completo bem-estar pode ser atingido por muitos, independentemente da presença ou não de doenças (Ramos, 2003). Atualmente, no Brasil, - Ministério da Saúde criou a política nacional de saúde da pessoa idosa, que tem por objetivo, no âmbito do SUS, garantir atenção integral à saúde da população idosa, enfatizando o envelhecimento saudável e ativo, tendo em vista o paradigma da capacidade funcional (Veras, 2009).

A saúde para os idosos é um fenômeno que varia para cada pessoa, de acordo com as experiências e condições de vida que cada uma teve ao longo da vida. Segundo Joia, Ruiz e Donalisio (2007), a satisfação com a vida é um julgamento cognitivo de alguns domínios específicos na vida, como: saúde, trabalho, condições de moradia, relações sociais, autonomia, entre outros, ou seja, reflete o bem-estar individual.

Segundo Ramos (2003, p.794):

Na verdade, o que está em jogo na velhice é a autonomia, ou seja, a capacidade de determinar e executar seus próprios desígnios. Qualquer pessoa que chegue aos oitenta anos capaz de gerir sua própria vida e determinar quando, onde e como se darão suas as atividades de lazer, convívio social e trabalho (produção em algum nível) certamente será considerada uma pessoa saudável. Pouco importa saber que essa mesma pessoa é hipertensa, diabética, cardíaca e que toma remédio para depressão - infelizmente uma combinação bastante freqüente nessa idade. O importante é que, como resultante de um tratamento bem-sucedido, ela mantém sua autonomia, é feliz, integrada socialmente e, para todos os efeitos, uma pessoa idosa saudável.

Se o conceito de saúde para o idoso é uma associação de múltiplos fatores, desta forma, determinar se um indivíduo está ou não saudável, é uma tarefa complexa, para tanto, algumas questões podem nortear a reflexão em torno do tema: Como tratar a velhice enquanto um processo de vida? Como a gestão pública deve garantir políticas e organizar os programas para garantir uma velhice feliz? Quais as necessidades desta população? Talvez um caminho inicial para fazer apontamentos e reflexões sobre esta questão seja garantir voz aos sujeitos idosos, ouvir deles como entendem a saúde, que fatores são essenciais para que se sintam saudáveis, e quais interferem negativamente neste processo, pois, sua percepção pode nos brindar com fatores diversos daqueles que já conhecemos, dando-nos novos parâmetros para planejar ações e políticas para este segmento. Assim sendo, o objetivo deste estudo foi conhecer a concepção de saúde segundo relato de idosos residentes em ambiente urbano. 


\title{
Metodologia
}

\section{Tipo de pesquisa}

O desenho metodológico seguiu a descrição de uma pesquisa qualitativa e descritiva. A pesquisa qualitativa em saúde segundo Minayo (2004, p.22):

\begin{abstract}
Trabalha com o universo de significados, motivações, aspirações, crenças, valores e atitudes do ser humano, o que corresponde a um espaço mais profundo das relações, dos processos e dos fenômenos que não podem ser reduzidos à operacionalização de uma variável.
\end{abstract}

Já o foco essencial dos estudos de natureza descritiva é o desejo de conhecer a comunidade, seus traços característicos e seus problemas (Trivinos, 1995).

\section{População do estudo}

A população do estudo foi composta por idosos com mais de sessenta anos, residentes no ambiente urbano do município de Chapecó em Santa Catarina. A amostra foi delimitada intencionalmente por 17 idosos residentes no ambiente urbano, entre homens e mulheres, para dar conta das questões que surgiram no decorrer da pesquisa.

\section{Instrumentos de coleta}

Para que os objetivos desta pesquisa fossem alcançados e considerando a natureza do estudo, optouse por uma entrevista semiestruturada. A obtenção das informações ocorreu com base em um roteiro previamente elaborado, com questões norteadoras sobre o entendimento do que é saúde para o idoso e os fatores que interferem neste processo. Este roteiro assumiu um caráter de linha norteadora para a condução da entrevista, ao mesmo tempo, desencadeou a liberdade de expressão dos entrevistados, estimulando e incentivando a espontaneidade das opiniões. As entrevistas foram gravadas e, posteriormente, transcritas sem alterações.

\section{Procedimentos de coleta dos dados}

Primeiramente, a partir do mapa do município de Chapecó, foi realizado o sorteio dos bairros Santo Antônio, Bela Vista, Alvorada, Efapi, Líder, Pinheirinho e Seminário; após, foi entregue, aos pesquisadores, um mapa, com todas as ruas dos bairros. O ponto inicial para coleta era um cruzamento de duas ruas, demarcado pelo pesquisador; este seguia pelo lado direito da rua, e, a cada duas casas, a primeira era selecionada e o pesquisador realizava a visita; se havia idoso, convidava para participar da pesquisa e, depois de informado sobre as finalidades da pesquisa, sua relevância, objetivos, métodos, benefícios previstos, bem como a forma como seriam coletados os dados, se o idoso concordasse em participar da pesquisa, assinava o termo de consentimento livre e esclarecido, e a entrevista era realizada. A pesquisa em questão foi aprovada pelo comitê de ética da instituição.

\section{Análise dos dados}

Os dados foram analisados de acordo com a proposição de Minayo (2004) que preconiza os seguintes passos:

1 Ordenação dos dados: etapa de transcrição das observações, releitura do material e organização dos relatos, compondo um corpo teórico.

2 Classificação dos dados: processo de leitura exaustiva e repetida dos textos, constituição de um "corpus" de comunicação, leitura transversal de cada corpo como recorte de "unidade de registro", enxugamento dos dados mais relevantes. 
3 Análise final e elaboração das categorias analíticas: fase onde se levam em conta os objetivos da pesquisa e os temas que emergem das observações e se faz articulação dos dados com o referencial teórico definindo-se as categorias analíticas.

Após análise dos resultados, segue a discussão a respeito de cada item pesquisado.

\section{Resultados e discussão}

A pesquisa realizada teve a participação de 17 idosos, residentes no ambiente urbano, em diferentes bairros do município de Chapecó, SC. A média de idade foi de setenta anos, com faixa etária de 69 anos. Destes, 13 eram mulheres e quatro homens. Quanto ao estado civil, dez eram viúvos(as), seis casados(as) e um solteiro.

Quando realizada a entrevista, o idoso(a) era questionado sobre o que era saúde para ele. Após ordenação e classificação dos dados foi realizada análise de conteúdo e as seguintes categorias analíticas emergiram do texto:

\section{$1^{\text {a }}$ categoria: autonomia, funcionalidade e liberdade}

No que tange às várias alterações fisiológicas provocadas pelo processo de envelhecimento, entre elas estão o enfraquecimento do tônus muscular e da constituição óssea, o que pode levar à mudança na postura do tronco e membros inferiores, exacerbando, ainda mais, as curvaturas da coluna torácica e lombar. Além disso, as articulações ficam mais enrijecidas, reduzindo os movimentos e produzindo alterações no equilíbrio e na marcha. Ocorrem, também, alterações nos reflexos de proteção e no controle do equilíbrio, prejudicando, assim, a mobilidade corporal, colocando o indivíduo em situação de risco para ocorrência de quedas e fraturas. Este quadro provoca declínio no desempenho funcional, e esse fato altera, completamente, a qualidade da saúde dos idosos (Pelegrin et al., 2008).

Entre os idosos, as condições crônicas tendem a se manifestar de forma mais frequente e, embora não sejam fatais, comprometem, de forma significativa, a funcionalidade do idoso, tornando-o dependente para realizar as atividades do cotidiano, o que gera frustração. Situação que se pode observar no relato de O.B., setenta anos:

"A gente tem que ter saúde pra ter algum ânimo de fazer alguma coisa, porque senão, não é nada".

O envelhecimento é uma aspiração natural de qualquer sociedade, mas, para que seja plena, é necessário manter a capacidade funcional, a autonomia e independência, só assim o idoso sentir-se-á feliz. O conceito de capacidade funcional está focado na habilidade que a pessoa tem de desempenhar as atividades do cotidiano, como: alimentar-se, vestir-se e cuidar da higiene (Pelegrin et al., 2008). Quando a capacidade funcional e autonomia estão preservadas, pode-se afirmar que o idoso é livre.

O conceito de capacidade funcional é extremamente relevante para os idosos, já que, na velhice, a saúde é resultante da interação entre: as dimensões física e mental, independência na execução de atividades básicas e instrumentais da vida diária, integração social, suporte familiar e independência econômica, sendo este um novo paradigma de saúde, de aspecto multidimensional (Ramos, 2003).

Do ponto de vista da saúde pública, a capacidade funcional surge como um conceito mais adequado para instrumentalizar e operacionalizar a atenção à saúde do idoso. Nesse sentido, ações preventivas, assistenciais e de reabilitação, para melhoria e/ou conservação da capacidade funcional, são essenciais para que se promova o bem viver da população idosa.

Nesta narrativa observa-se quanto é importante, para o idoso, manter uma boa capacidade funcional e independência:

"Sim tenho saúde, porque aqui dentro da minha casa, faço tudo, a comida, limpeza de panela, só não lavo roupa e não limpo o chão, mas no mais eu faço tudo. Eu vou capinar na horta, eu planto minhas plantinhas tudo ali, minha horta é grande". (C.O., 64 anos) 
Maciel e Guerra (2008), afirmam que a manutenção de uma vida livre de restrições quanto à funcionalidade pode colaborar para a redução do risco de óbito em idosos, pois a dependência temse apresentado como um agente de morbimortalidade, tanto isoladamente, como associada ao estilo de vida, doenças crônico-degenerativas, disfunções neuropsíquicas e fatores sociodemográficos ou socioeconômicos. Manter-se independente, autônomo e livre para ir e vir é fundamental para que o ser humano viva em plenitude.

Autonomia, autorresponsabilização, exercícios físicos, flexibilidade, disponibilidade para aprendizagem, ausência de identificação etária, independência, e liberdade são características que vêm se tornando indicativas de um envelhecimento feliz, e vêm se constituindo como fatores determinantes para a saúde do idoso.

\section{$2^{a}$ categoria: saúde é a globalidade da vida}

No Brasil, desde a década de 1960, a população com mais idade vem crescendo aceleradamente, devido à diminuição das taxas de fecundidade e de mortalidade nas faixas etárias mais elevadas. Acredita-se, também, que outro fator que contribuiu foi a melhoria das condições de saneamento básico e os avanços tecnológico-científicos na área da saúde (Souza, Lopes, 2007).

Segundo Scherer et al. (2007), para alcançarmos a almejada vida com saúde, precisamos: dormir bem, nos alimentar de forma balanceada, praticar atividades físicas, ter paz de espírito, estar de bem com a vida, ter a consciência tranquila, ter uma família e nos relacionar bem com ela, nos divertir e ter amigos. Este conceito de saúde apresentado pelo autor pode ser percebido no relato da idosa:

"Saúde é tudo, o bem estar do corpo, dos sentimentos, dos convívios e relações, no mundo no qual estamos inseridos..., eu tenho muita saúde". (E.B.T., 65 anos)

Outro fator importante, quando pensamos a saúde de uma maneira global, são os fatores culturais, pois a cultura de um indivíduo pode ser um fator protetor da saúde, ou de risco, e predispor ao adoecimento, dependendo do contexto. É preciso considerar que os aspectos culturais envolvidos na questão da saúde e da doença só podem ser compreendidos em contextos específicos (Scherer et al., 2007).

O termo saúde global é compreendido como uma junção biopsicossocial de fatores que definem quanto o ser humano sente-se saudável, e como cada determinante - sejam os biológicos, psicológicos e/ ou sociais - interfere na condição de saúde de uma população. A seguir, um relato que reforça a concepção de que saúde é multifatorial e global:

"Saúde que eu entendo em primeiro lugar é estar de bem com a vida, isso já é o primeiro, outra coisa se alimentar bem e corpo bom, estar de bem com os vizinhos, amigos, filhos. Estou com muita saúde graças a Deus, não tomo nenhum medicamento com a idade que eu tenho". (C.E., 70 anos)

Saúde, no processo de envelhecer, passa a ser uma percepção que cada um constrói sobre si mesmo, baseado em sua história e expectativas individuais, constituindo-se, portanto, numa jornada, e não num fim. De maneira geral, o que se pôde observar nas narrativas de alguns idosos entrevistados é que a saúde é um fato construído ao longo da vida, num constante processo de cuidar de si:

\footnotetext{
"Saúde é tudo, cuidar do dinheiro, das amizades, da família, do que se usa no alimento é tudo, hoje eu tenho saúde, mas sofri de garoto e, tenho exemplo de sofrimento em casa com a esposa. A melhor felicidade que uma pessoa pode ter é com saúde, poder andar, ir e vir, se fosse para viver, eu peço a Deus que me dê à vontade de andar e ter saúde". (A.M., 76 anos)
} 
Ao destacar a saúde como um processo vivenciado ao longo da história de cada um, percebe-se a importância do cuidado com a saúde em seu aspecto integral, para assim chegar a uma idade mais avançada e poder afirmar que é saudável. Nesse sentido, observa-se a relevância do estudo, pois nada mais fidedigno para se compreender o conceito de saúde para o idoso, que avaliar a concepção de uma pessoa que tem mais anos de vida.

\section{$3^{a}$ categoria analítica: família e rede de apoio}

Atualmente, uma questão que tem grande relevância em relação à velhice está, portanto, relacionada ao equilíbrio entre as necessidades e as exigências mínimas dos idosos e a capacidade assistencial disponível para atendê-las, em nível familiar ou coletivo, pois, nessa fase da vida, tais aspectos adquirem características especiais (Lebrão, Laurenti, 2005).

Fazendo uma análise de estudos já realizados sobre a relação familiar e o idoso, estes demonstram que a família, por meio do seu apoio, tem tido um papel muito importante para o bem-estar dos idosos. No entanto, as interações entre os familiares podem variar entre homens e mulheres, regiões mais ou menos urbanizadas, os mais ricos em comparação com os mais pobres, tradições familiares, intervenção de apoios institucionais e características socioeconômicas do país (Camargos, Machado, Rodrigues, 2007).

As famílias, hoje, continuam sendo a principal fonte de sustento e cuidado dos idosos. Elas oferecem apoio social, funcional, econômico ou material e afetivo. Dentre as várias assistências que a família presta aos idosos, podem-se destacar: o apoio às tarefas domésticas, passeios e outras atividades da vida diária, companhia, apoio afetivo em tempos normais e de crise, transporte e acompanhamento a diversos lugares, cuidados com a medicação e auxílio no caso de doença - enfim, é ela que apoia o idoso na maior parte do tempo (Rodrigues, Watanabe, Derntl, 2006).

A família aparece, em nosso estudo, como um fator essencial para que o idoso se perceba saudável; realmente, é um fator de proteção, quando presta o cuidado, proporciona atenção, carinho e companhia. A seguir, o relato de uma idosa, que mostra quanto a família é valorizada para quem envelhece:

"A melhor coisa, em primeiro lugar, é a família da gente, a gente vive bem, com a família, com os netos, e assim, em primeiro lugar, é a família". (A.S.A., 71 anos)

O idoso tem receio do abandono e da incompreensão. Essas questões aparecem na narrativa do idoso:

\footnotetext{
"Eu acho que é boa minha vida. Eu me sinto muito feliz. Moro com a minha filha aqui, convivemos muito bem... meu Deus... é o que a gente quer, quando ficamos velhos, que tenham paciência com a gente, que nos cuidem...". (E.T., 63 anos)
}

A pessoa idosa, geralmente, é mais fragilizada emocionalmente, quando comparada com uma pessoa mais nova. Por isso, precisa, sempre, de uma grande rede de apoio para ter uma vida tranquila, saudável e satisfatória; mas a família, hoje, ainda assume um papel central na rede de apoio. A presença da família e o cuidado que ela presta dão significado à vida do idoso e the garantem um papel social no pequeno grupo, fator essencial para viver feliz.

\section{Considerações finais}

O estudo conclui que a percepção de saúde relatada pelo idoso está centrada em multifatores, mas, prioritariamente, para se sentirem saudáveis, precisam garantir um bom nível de independência e autonomia, pois a presença ou não de doenças crônicas e o uso de medicação não foram relatados como fatores importantes para o conceito de saúde; isto quer dizer que, mesmo o idoso estando em tratamento para alterações próprias do contexto do envelhecimento, se realiza as atividades do seu cotidiano, sente-se com saúde. Outro fator importante observado no estudo foi o entendimento 
do idoso de que a saúde é construída historicamente, pela forma com que cada um cuida de si ao longo da vida, bem como de que forma constrói sua rede de apoio, convívio e família. A saúde, nesta perspectiva, portanto, é compreendida pelo idoso como uma categoria de aspectos biopsicossociais, e não como algo no singular.

A corresponsabilização do idoso com sua saúde é um fator a se destacar no estudo, pois, em seus relatos, estão se colocando como atores do processo de viver e envelhecer, onde a família, a rede de apoio, os recursos financeiros e o nível de independência são elementos importantes; porém, a forma como cada sujeito viveu sua vida, os acessos que teve, ou não, quanto à educação, estilo de vida, saúde e trabalho, são determinantes no processo, e, portanto, os idosos se percebem como sujeitos que participaram da construção da saúde vivida no hoje, sobretudo, quando consideram as opções realizadas ao longo do processo de viver.

Sugere-se que sejam realizadas mais pesquisas sobre a concepção dos idosos em torno dos vários temas que emergiram nesta pesquisa, constituindo novas categorias para se discutir o envelhecimento, pois, não há colaborador mais importante para falar da velhice do que aquele que viveu e vive a experiência de envelhecer. Ouvir os idosos é essencial para entendermos seu cotidiano e conhecermos as particularidades que os números não apresentam, e, a partir destes novos elementos, podem-se planejar serviços, ações, diretrizes e políticas destinados ao bem viver dos idosos.

\section{Colaboradores}

Fátima Ferretti e Rosane Paula Nierotka trabalharam juntas em todas as etapas de produção do manuscrito; Márcia Regina da Silva trabalhou na revisão e produção final do artigo.

\section{Referências}

CAMARGOS, M.C.S.; MACHADO, C.J.; RODRIGUES, R.N. A relação entre renda e morar sozinho para idosos paulistanos - 2000. Rev. Bras. Est. Pop., v.24, n.1, p.37-51, 2007.

FERREIRA, A.B. et al. Programa de atenção particularizada ao idoso em unidades básicas de saúde. Saude Soc., v.18, n.4, p.776-86, 2009.

FERRETTI, F.; SILVA, M.R.; NIEROTKA, R.P. Condições de saúde de idosos residentes no ambiente rural e urbano do município de Chapecó. Projeto de pesquisa de longa duração, modalidade balcão de projetos, artigo 170 e PIBIC/FAPE. Chapecó: UNOCHAPECÓ, 2009.

INOUYE, K.; PEDRAZZANI, E.S.; PAVARINI, S.C.L. Octogenários e cuidadores: perfil sóciodemográfico e correlação da variável qualidade de vida. Texto Contexto Enferm., v.17, n.2, p.350-7, 2008.

JOIA, L.C.; RUIZ, T.; DONALISIO, M.R. Condições associadas ao grau de satisfação com a vida entre a população de idosos. Rev. Saude Publica, v.41, n.1, p.131-8, 2007.

LEBRAO, M.L.; LAURENTI, R. Saúde, bem-estar e envelhecimento: o estudo SABE no Município de São Paulo. Rev. Bras. Epidemiol., v.8, n.2, p.127-41, 2005.

LIMA-COSTA, M.F. et al. A influência de respondente substituto na percepção da saúde de idosos: um estudo baseado na Pesquisa Nacional por Amostra de Domicílios (1998, 2003) e na coorte de Bambuí, Minas Gerais, Brasil. Cad. Saude Publica, v.23, n.8, p.1893-902, 2007.

MACIEL, Á.C.C.; GUERRA, R.O. Limitação funcional e sobrevida em idosos de comunidade. Rev. Assoc. Med. Bras., v.54, n.4, p.347-52, 2008. 
MINAYO, M.C.S. O desafio do conhecimento: pesquisa qualitativa em saúde. 7.ed. São Paulo: Hucitec/Abrasco, 2004.

PELEGRIN, A. et al. Idosos de uma Instituição de Longa Permanência de Ribeirão Preto: níveis de capacidade funcional. Arq. Cienc. Saude, v.15, n.4, p.182-8, 2008.

RAMOS, L.R. Fatores determinantes do envelhecimento saudável em idosos residentes em centro urbano: Projeto Epidoso, São Paulo. Cad. Saude Publica, v.19, n.3, p.793-7, 2003.

RODRIGUES, S.L.A.; WATANABE, H.A.W.; DENTL, A.M. A saúde de idosos que cuidam de idosos. Rev. Esc. Enferm. USP, v.40, n.4, p.493-500, 2006.

SCHERER, M.D.A. et al. O viver saudável e o viver não saudável: o significado para mulheres maduras e ativas. Cad. Saude Coletiva, v.15, n.1, p.131-46, 2007.

SOUZA, A.C.; LOPES, M.J.M. Práticas terapêuticas entre idosos de Porto Alegre: uma abordagem qualitativa. Rev. Esc. Enferm., v.41, n.1, p.52-6, 2007.

TRIVINOS, A.N.S. Introdução à pesquisa em ciências sociais. São Paulo: Atlas, 1995.

VERAS, R.P. Envelhecimento populacional contemporâneo: demandas, desafios e inovações. Rev. Saude Publica, v.43, n.3, p.548-54, 2009.

FERRETTI, F; NIEROTKA, R.P.; SILVA, M.R. Concepción de salud según relato de ancianos que residen en el ambiente urbano Interface - Comunic., Saude, Educ., v.15, n.37, p.565-72, abr./jun. 2011.

La salud es un fenómeno que difiere de acuerdo con los aspectos biológicos, culturales, ambientales, sociales e históricos y el modo como cada ser humano vivió su vida. Esta investigación descriptiva con una muestra de 17 ancianos ha tratado de conocer la concepción de salud de ancianos que residen en ambiente urbano. En la recolección de los datos se optó por una entrevista semi-estructurada. El análisis de los datos a demuestra que la concepción de salud estuvo centrada en la manutención de la independencia, en el apoyo de la familia y en el sentirse responsable por el modo de vivir la vida. Al percibirse como actor del proceso de vivir y envejecer demuestra que el anciano asume su responsabilidad por la salud vivida hoy, evidenciando un cambio de comportamiento social y político, de la pasividad hacia la participación activa en el proceso de la vida.

Palabras clave: Salud. Anciano. Ambiente urbano.

Recebido em 24/05/2010. Aprovado em 28/10/2010 